\title{
Transarterial embolization of an anterior fossa cranial base dural arteriovenous fistula
}

\author{
Brian Lee, M.D., Ph.D., Vivek A. Mehta, M.D., Arun P. Amar, M.D., \\ Matthew S. Tenser, M.D., and William J. Mack, M.D. \\ Department of Neurosurgery, University of Southern California, Los Angeles, California
}

\begin{abstract}
Open surgical disconnection has long been the treatment of choice for dural arteriovenous fistulas (dAVFs) of the anterior cranial fossa. However, advanced patient age and the presence of medical comorbidities can substantially increase the risk of craniotomy and favor a less invasive endovascular approach. Optimal positioning within the distal ophthalmic artery, beyond the origin of the central retinal branch, is achievable using current microcatheter technology and embolic materials. Here we present the case of an 88-year-old female with an incidentally discovered $\mathrm{dAVF}$ of the anterior cranial fossa. Angiographic cure was achieved with one-stage Onyx embolization.

The video can be found here: http://youtu.be/KVEOfUIECQM.

(http://thejns.org/doi/abs/10.3171/2014.V2.FOCUS14174)
\end{abstract}

KEY Words $\bullet$ embolization $\bullet$ anterior fossa $\bullet$
dural arteriovenous fistula $\bullet$ dAVF $\bullet$ Onyx $\bullet$ video

Manuscript submitted May 1, 2014.

Accepted May 27, 2014.

Please include this information when citing this paper: DOI:

10.3171/2014.V2.FOCUS14174.

Address correspondence to: Dr. Brian Lee, University of Southern California, Neurosurgery, 1200 N State Street, Suite 3300, Los Angeles, California 90033. email: brianlee@usc.edu. 